Research article

\title{
Cerebellar Insulin/IGF-1 signaling in diabetic rats: Effects of exercise training
}

\author{
Mariana Eiras Borges ${ }^{a}$, Alessandra Mussi Ribeiro ${ }^{a}$, José Rodrigo Pauli ${ }^{\mathrm{b}}$, \\ Luciana Mendonça Arantes ${ }^{e}$, Eliete Luciano ${ }^{c}$, Leandro Pereira de Moura ${ }^{b}$, \\ José Alexandre Curiacos de Almeida Leme ${ }^{\mathrm{d}}$, Alessandra Medeiros ${ }^{\mathrm{a}}$, \\ Natália Oliveira Bertolini ${ }^{c}$, Clarice Yoshiko Sibuya ${ }^{c}$, Ricardo José Gomes ${ }^{\mathrm{a}, *}$ \\ a Department of Biosciences, São Paulo Federal University (UNIFESP), Santos, São Paulo, Brazil \\ b Sport Science Course, University of Campinas, UNICAMP, Limeira, São Paulo, Brazil \\ c Department of Physical Education, São Paulo State University (UNESP), Rio Claro, São Paulo, Brazil \\ d Department of Physical Education, Catholic University Center Unisalesiano, Lins, São Paulo, Brazil, Brazil \\ e Departament of Physical Education, University Center of Patos de Minas, Patos de Minas, Minas Gerais, Brazil, Brazil
}

\section{H I G H L I G H T S}

- The uncontrolled diabetes mellitus leads to brain changes similar to neurodegenerative diseases like Parkinson's Disease.

- Aerobic exercise training can be used as treatment and prevention of neurodegeratives diseases, especially in patients with DM.

- Aerobic training may be able to alters some proteins related to insulin/IGF-1 signaling in cerebellum of DM.

\section{A R T I C L E I N F O}

\section{Article history:}

Received 14 July 2016

Accepted 23 December 2016

Available online 26 December 2016

\section{Keywords:}

Diabetes

Exercise

Cerebellum

\begin{abstract}
A B S T R A C T
The Diabetes Mellitus (DM) is a chronic disease associated with loss of brain regions such as the cerebellum, increasing the risk of developing neurodegenerative diseases such as Parkinson's disease (PD). In the brain of diabetic and PD organisms the insulin/IGF-1 signaling is altered. Exercise training is an effective intervention for the prevention of neurodegerative diseases since it release neurotrophic factors and regulating insulin/IGF-1 signaling in the brain. This study aimed to evaluate the proteins involved in the insulin/IGF-1 pathway in the cerebellum of diabetic rats subjected to exercise training protocol. Wistar rats were distributed in four groups: sedentary control (SC), trained control (TC), sedentary diabetic (SD) and trained diabetic (TD). Diabetes was induced by Alloxan (ALX) ( $32 \mathrm{mg} / \mathrm{kg}$ b.w.). The training program consisted in swimming 5 days/week, $1 \mathrm{~h} /$ day, during 6 weeks, supporting an overload corresponding to $90 \%$ of the anaerobic threshold. At the end, cerebellum was extracted to determinate the protein expression of GSK-3 $\beta$, IR $\beta$ and IGF-1R and the phosphorylation of $\beta$-amyloid, Tau, ERK1 + ERK2 by Western Blot analysis. All dependent variables were analyzed by one-way analysis of variance with significance level of $5 \%$. Diabetes causes hyperglycemia in both diabetic groups; however, in TD, there was a reduction in hyperglycemia compared to SD. Diabetes increased Tau and $\beta$-amyloid phosphorylation in both SD and TD groups. Furthermore, aerobic exercise increased ERK1 + ERK2 expression in TC. The data showed that in cerebellum of diabetic rats induced by alloxan there are some proteins expression like Parkinson cerebellum increased, and the exercise training was not able to modulate the expression of these proteins.
\end{abstract}

(c) 2016 Elsevier Ireland Ltd. All rights reserved.

\footnotetext{
* Corresponding author at: Department of Biosciences, São Paulo Federal University (UNIFESP), Silva Jardim Street, 136, Santos, São Paulo, Brazil.

E-mail address: ricardojosegomes@yahoo.com.br (R.J. Gomes).
}

\section{Introduction}

Diabetes Mellitus (DM) is a chronic disease characterized by hyperglycemia which may causes damage to eyes, kidneys, heart and central nervous system (CNS) [1]. Specifically, DM can causes damage in brain regions such as cerebellum and hypothalamus, and as consequence increasing risk of neurodegenerative diseases, 
as Alzheimer's Disease (AD) and Parkinson's disease (PD) [2,3,4]. $\mathrm{PD}$ is characterized by progressive loss of dopaminergic neurons in the substantia nigra pars compacta accompanied by an expressive reduction of striatal dopamine levels, an important neurotransmitter in neuronal modulation that may compromise the motor circuit [5]. Furthermore, mutations in $\alpha$-synuclein form part of the intracytoplasmic Lewy bodies, contribute to the degeneration of dopaminergic neurons $[2,6]$.

The DM and PD features are distinct, although genetic factors associated with environmental aspects can trigger a cascade of uncommon events to both diseases [7]. Kotagal et al. (2013) evaluated patients with PD and DM, and showed greater postural instability and gait difficulty when compared to patients with only PD, concluding that DM exacerbates the symptoms of PD through mechanisms other than nigrostriatal dopaminergic denervation. Besides the typical motor impairment due to because $\alpha$-synuclein protein, previous studies $[8,9,10]$ showed that there is an increase of tau protein in the patient brains with $\mathrm{PD}$, suggesting that tau accumulation increases the risk of developing PD, and as a consequence may occur increase of the risk of cognitive decline. Important to mention that, in patient brains with DM there are hyperphosphorylation of tau protein [11], wich perhaps may be a risk to PD.

Insulin-like growth factor (IGF-1) appears to be another protein associated with neurodegenerative diseases. Previous studies have showed that IGF-1 can protect the brain against the loss of dopaminergic neurons [12], and that IGF-1 concentration in the cerebellum of diabetic rat is decreased [13], suggesting a relationship between the DM and PD.

Notwithstanding, Arantes et al. [14] showed that diabetic animals have loss body balance and that the aerobic exercise training reduced this loss. Exercise training constitutes an effective intervention in disorders such as $\mathrm{DM}, \mathrm{AD}$ and $\mathrm{PD}$, attenuating or inhibiting their progression [15,16]. Different mechanisms have been suggested for explaining the benefits of exercise training in the prevention and management of neurodegenerative disorders, such as the release of neurotrophic factors and the angiogenesis, thereby facilitating neurogenesis and synaptogenesis $[17,18]$. The exercise training increases the central concentration of insulin [19], and IGF-1 [20], in addition, decreasing the concentrations of Tau and amyloid precursor protein (APP) proteins in diabetic rats [21].

For these reasons, the aim of this study was to evaluate the expression of the proteins involved in the insulin/IGF-1 pathway in the cerebellum of diabetic rats submitted to an aerobic exercise training protocol.

\section{Methods}

\subsection{Animals}

Thirty-eight male Wistar rats (175-200 g) were housed in cages $(45 \times 35 \times 15 \mathrm{~cm} ; 4-5$ animals per cage) with water and food ad libitum, under controlled conditions of temperature $\left(23-25^{\circ} \mathrm{C}\right)$ and light/dark cycle (12-12 h, lights were turned on at 7:00 a.m. and turn off at 7:00 p.m.). All experiments involving animals were conduct according to the Brazilian law for the use of animals in scientific research (Law Number 11.794) and all procedures described received the approval of local ethics committee of São Paulo Federal University (\# 2012/00217).

\subsection{Proceedings}

Diabetes was induced by i.v. injection of alloxan (ALX$32 \mathrm{mg} / \mathrm{kg}$ b.w.; Sigma, USA). After 5 days, blood samples were obtained from rats in the fed state to determine plasma glucose concentration, which were included in the study only animals which presented glycemia between 11 and $28 \mathrm{mmol} / \mathrm{L}$ Animals were randomly distributed into four groups: control sedentary (CS), control trained (CT), diabetic sedentary (DS) and diabetic trained (DT).

\subsection{EXERCISE training PROTOCOL}

The exercise training consisted in 5 swimming sessions/week, per 4 weeks, $1 \mathrm{~h}$ per session with an overload corresponding to $90 \%$ of the anaerobic threshold (AT). All groups were adapted to swimming training for 5 days before starting the protocol. Before undergoing the lactate minimum protocol, all the animals were adapted to water. The water temperature was maintained at $31 \pm 1{ }^{\circ} \mathrm{C}$. The purpose of the adaptation period was to reduce stress in the animals.

\subsection{Lactate minimum test}

AT was determined by lactate minimum test (LACmin) adapted to rats $[22,23]$. The LACmin consists of performing a short period of supramaximal exercise to induce hyperlactemia before starting the incremental exercise phase. To produce hyperlactemia, the rats were induced to jump into the water for $6 \mathrm{~min}$ (30-s exercise interrupted by 30 -s rest) carrying an overload corresponding to $50 \%$ of b.w. (the overload was added using lead fish sinkers strapped to the chest) ia a cylinder tank, $50 \mathrm{~cm}$ deep, and $25 \mathrm{~cm}$ in diameter, filled with water at $31 \pm 1^{\circ} \mathrm{C}$. After 9-min recovery interval, the rats were submitted to an incremental test consisting of swimming while carrying overloads of $4.5,5.0,5.5,6.0$, and $7.0 \%$ of body weight. During this incremental phase, each overload lasted $5 \mathrm{~min}$ and was follow by a 30-s rest, during which, blood samples were taken for subsequent lactate measurement. The BLM (the load corresponding to the nadir of the blood lactate vs. workload, as a\% of body weight plot) was estimated from the zero-gradient tangent to a spline function fitting the exercise blood lactate data. The AT, considered as the parameter for aerobic capacity, was equivalent to the zero derivative of a second-older polynomial fit, which was obtain from the ratio between the lactate concentrations and exercise intensity. The LACmin was performed at baseline and at the fourth week of training in order to adjust the overload of each rat.

\subsection{Euthanasia}

The rats were euthanized (by decapitation), $48 \mathrm{~h}$ after their last exercise bout and blood samples were collected for glucose measurements (by a colorimetric method [24].

\subsection{Tissue preparation}

Cerebellum was carefully excised in ice and weighed on a precision balance. Afterward, cerebellum tissues were stored at $-80^{\circ} \mathrm{C}$ until analyses. The protein content of cerebellum was measured by the method of Lowry et. al. (1951). The tissue was homogenized in an extraction buffer (mM) (1\% Triton X-100, 100 Tris, $\mathrm{pH} 7.4$, containing 100 sodium pyrophosphate, 100 sodium fluoride, 10 EDTA, 10 sodium vanadate, 2 PMSF, and $0.1 \mathrm{mg}$ of aprotinin $/ \mathrm{mL}$ ), at $4{ }^{\circ} \mathrm{C}$ in a Beckman $70.1 \mathrm{Ti}$ rotor (Palo Alto, CA, USA), for $60 \mathrm{~s}$ at maximum speed and for $40 \mathrm{~min}$ by solubilizing, after that the samples were centrifuged by $15 \mathrm{~min}$ at $12000 \mathrm{rpm}$ to remove insoluble material. The supernatants of these tissues were used for protein quantification, using the Bradford method.

\subsection{Western blot assay}

In direct immunoblotting experiments, $0.2 \mathrm{mg}$ of protein extracts was separated by SDS- PAGE, transferred to nitrocellulose membranes, blocked for $2 \mathrm{~h}$ (Basal solution plus BSA 
Beta Amyloid Phosphorylation

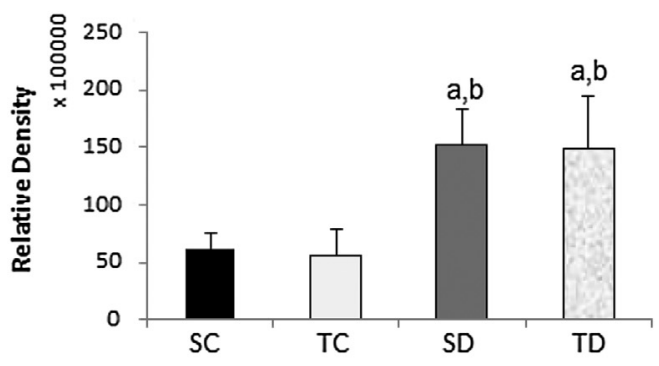

GSK-3 $\beta$ Expression

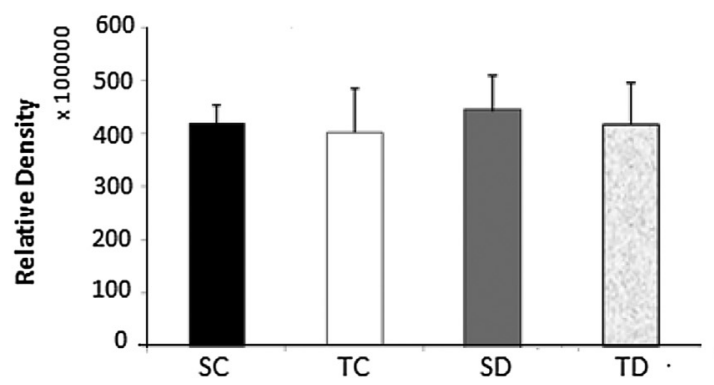

Tau Protein Phosphorylation

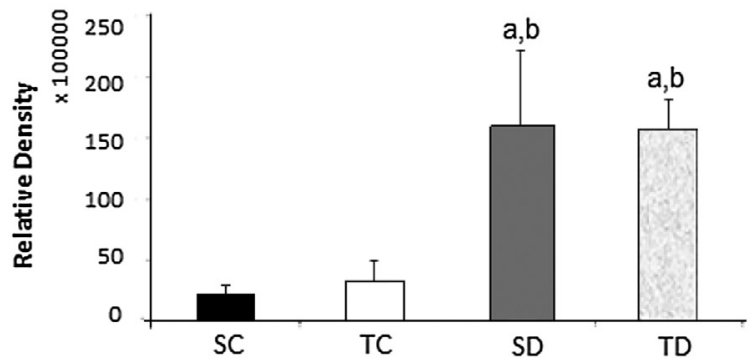

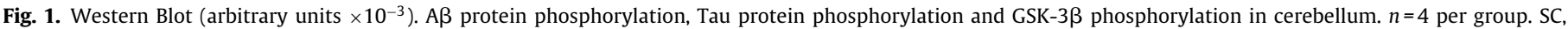
sedentary control; TC, trained control; SD, sedentary diabetic; and TD, trained diabetic. (one-way ANOVA, $P<0.05$; a compared to TC, b compared to SC).

IR $\beta$ Expression

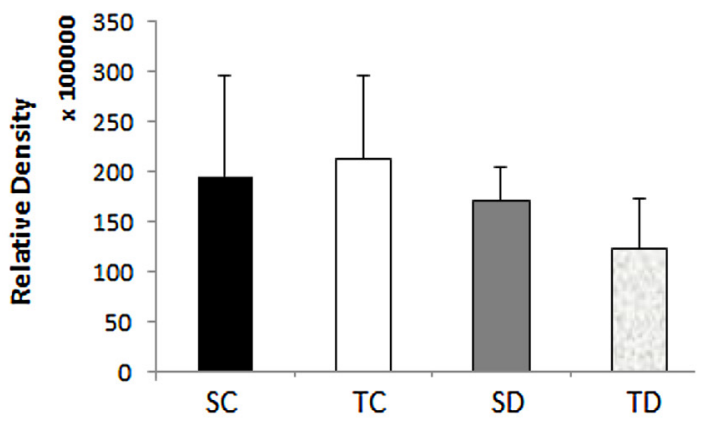

ERK1+ERK2 Phosphorylation

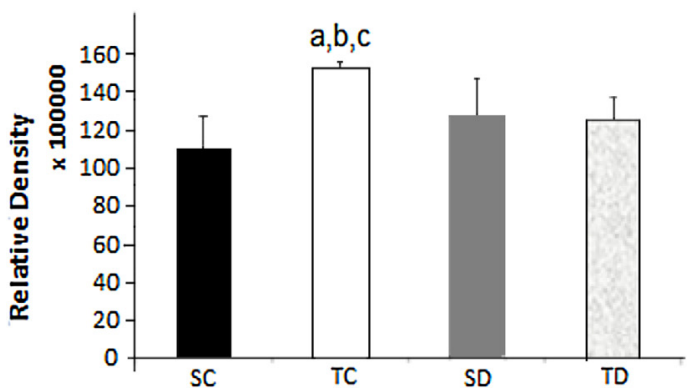

IGF-1R Expression

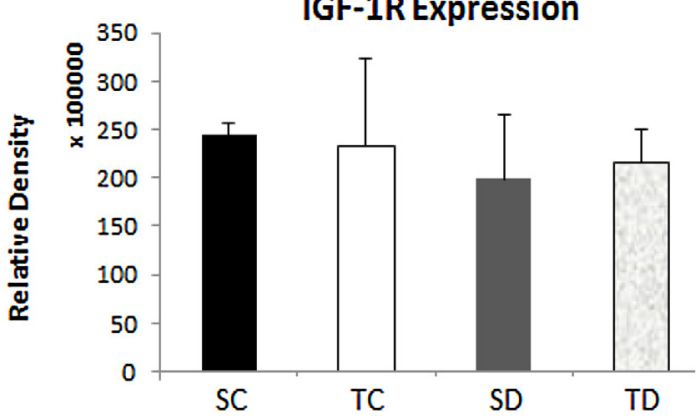

SC TC SD TD

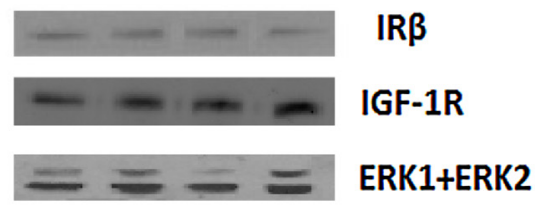

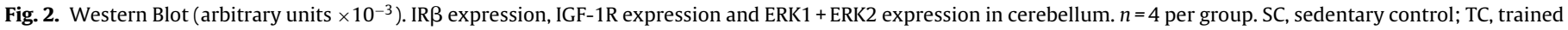
control; SD, sedentary diabetic; and TD, trained diabetic. (One-way ANOVA, $P<0.05$; a compared to TC, b compared to SC, c compared to SD).

$5 \%$, and then blotted with primary antibodies, anti-IRbeta, anti-IGF-1R, anti-phospho-tau, anti-phospho $\beta$-amyloid $(A \beta)$ protein, anti-phospho-ERK1 + ERK2 and anti-phospho-GSK3 $\beta$ (Abcam, Cambridge, UK). Chemiluminescent detection was perform with horseradish peroxidase-conjugate secondary antibodies (incubation, $2 \mathrm{~h}$ ). The visualization of protein bands was performer by exposure of membranes to RX-films.

\subsection{Statistical analyses}

All dependent variables were analyzed by one-way analysis of variance (one-way ANOVA) and a significance level of $p<0.05$ was use for all comparisons. The Newman- Keuls test was use for post hoc comparisons. 
Table 1

Blood glucose $(\mathrm{mg} / \mathrm{dL})$ and body weight $(\mathrm{g})$ after 6 weeks of training.

\begin{tabular}{lll}
\hline & Glucose $(\mathrm{mmol} / \mathrm{L})$ & Body Weight $(\mathrm{g})$ \\
\hline SC & $5,6 \pm 1$ & $379 \pm 55$ \\
TC & $5,8 \pm 0,9$ & $343 \pm 43$ \\
SD & $18 \pm 1,2 \mathrm{a}, \mathrm{b}$ & $277 \pm 49 \mathrm{a}, \mathrm{b}$ \\
TD & $16,6 \pm 1,3 \mathrm{a}, \mathrm{b}, \mathrm{c}$ & $327 \pm 54$ \\
\hline
\end{tabular}

SC, sedentary control; TC, trained control; SD, sedentary diabetic; and TD, trained diabetic. $n=10$ per group. (one-way ANOVA, $P<0.05$; a compared to TC, b compared to SC, c compared to SD).

\section{Results}

In this study, rats were trained with an overload corresponding to $90 \%$ of the AT. The diabetics animals (SD and TD) showed hyperglycemia, but aerobic exercise decreased blood glucose in TD. Diabetes reduced body weight (SD) and the exercise was able to decrease this in TD. Statistical analysis revealed an increase in tau protein phosphorylation levels in SD and TD when compared to $C T$ and CS groups in cerebellum. In relation to $A \beta$ phosphorylation, there was an increase in diabetic animals (SD and TD) when compared to control (TC and SC) (Fig. 1). Tau phosphorylation was increased in SD and TD when compared to TC and SC (Fig. 1). However, GSK-3 $\beta$ level in the cerebellum was not alters in the groups SD and TD (Fig. 1). The expression of proteins IR $\beta$ and IGF-1R were not significantly different between all groups (Fig. 2). Cerebellar ERK1 + ERK2 phosphorylation increased in TC rats when compared to other groups (SC, SD and TD) (Fig. 2 Table 1).

\section{Discussion}

This current study it was investigated the role of exercise training on proteins expressed in cerebellum that are associated to insulin/IGF-1 signaling pathway in ALX Type 1 diabetic rats. Previous studies have shown a possible relationship between dementia provoked by diabetes and neurodegenerative diseases such as PD and $\mathrm{AD}[25,26]$.

It is very well known that diabetic rats, induced by alloxan, have metabolic changes similar to DM1 in humans, such as hyperglycemia, polyuria and weight loss [27]. In our study, diabetic animals had significantly lower body weight and higher blood glucose compared with control groups. Nevertheless, the training protocol reduced blood glucose and decreased the body weight loss in TD. These results reflect the chronic adaptations induced by exercise training already seen in other studies [28,29].

Some studies have been showed that the insulin and IGF-1 concentrations decreased in the cerebellum of diabetic animals and the exercise training increased the IGF-1 peptide concentration [14,30]. In our study, no differences in insulin and IGF-1 receptors expressions (IGF-1R and IR $\beta$ ) in the cerebellum of diabetic rats were found. Notwithstanding, Diegues et al. [21] showed that aerobic exercise training may be able to increase the concentration of these proteins in the hippocampus of diabetic rats [21]. These findings suggested that brain areas may express differently receptors in response to exercise training.

The potential importance of IGF-1 was highlighted by the findings that increased $\mathrm{Ab}$ clearance from brain to periphery in animal models, by upregulating the entry of carrier proteins across the blood-brain barrier [31]. Blood levels and brain uptake of IGF-1 are elevated with exercise [31,32].

Insulin degrading enzyme (IDE) is also responsible for the degradation of beta amyloid protein preventing the formation of beta amyloid oligomers that are toxic to the central nervous system (CNS) [33]. However, IDE is more sensitive to insulin thus insulin resistance is responsible for the accumulation $A \beta$ impairing cognitive functions [34]. At the same time the signaling cascade
insulin/IGF-1 is responsible for controlling the phosphorylation of Tau protein, when there insulin/IGF-1 resistance, occurs hyperphosphorylation of Tau protein [35]. Tau hyperphosphorylation has been related to the engine deficit of these pathways [36,8]. It has been seen that diabetic organisms have decreased IGF- 1 and insulin in the brain and that this is related with the increase of $A \beta$ and Tau [37]. As already said, studies in the literature show the increase in $A \beta$ and Tau in brain area $[37,36]$, different from our study that showed increases of these proteins specifically in the cerebellum of diabetic animal. We also observed that exercise training for 6 weeks was not able to reduce the phosphorylation of these proteins. In a previous study, we showed that diabetic rats also had higher Tau and $A \beta$ phosphorylation in the hippocampus, but the same swimming training protocol was able to decrease the phosphorylation of Tau protein of diabetic animals [21]. Our findings indicate that exercise can act differently in different brain areas

There is evidence that high levels of GSK-3 $\beta$ in brain areas increase the risk of pathologies such as DM [38]. The GSK3- $\beta$ phosphorylation is controlled by AKT, moreover, GSK-3 $\beta$ expression is increased in brain regions associated with PD [39]. Then, inhibition of GSK-3 $\beta$ has been considered as a therapeutic target for PD [40]. The other therapeutic target to decrease GSK-3 $\beta$ is the physical training, by increases Akt phosphorylation and consequent decreased GSK-3 $\beta$ expression [41]. Nevertheless, in our study, we did not find significant differences between groups.

The extracellular signal-regulated kinases (ERK1/2) are related to cell survival, proliferation, differentiation memory formation and engaged with PD $[42,43]$. There are three lines of thought with regard to neurotoxicity $A \beta$ on ERK, the first line shows that activation of ERK is able to protect the toxicity of neurons $A \beta(2)[44,45]$, other studies have shown that $A \beta$ had no effect on ERK [46] and there are also other work showing that ERK activation by Ab promotes cell death [47].

After activation of IR occurs phosphorylation of insulin receptor substrate 1 (IRS-1), which can be recognized by several kinases, as ERK. [48] showed by culturing animal hippocampal cells, activation of ERK inhibits phosphorylation of Akt, while the phosphorylation of Akt suppresses the activation of ERK, in addition, showed that insulin acts as protector cells hippocampus. In our study, cerebellar ERK1 + ERK2 phosphorylation increased in TC rats when compared to other groups. Our results are in agreement with other studies in the literature that suggest that exercise training acts as neuroprotector agent and the ERK would be acting as anti-apoptotic factor, modulating survival and cell proliferation [49,50]. Exercises training does not alter the phosphorylation of ERK1 + ERK2 in diabetcs groups, maybe because insulin is a regulator of ERK, as shown in a previous study [48].

In summary, our work demonstrated that aloxan diabetic animals showed higher cerebellum $A \beta$ and Tau phosphorylation, similarly to Parkinsonian cerebellum. Our exercise training protocol was not able to reduce the phosphorylation of tau protein and $\mathrm{A} \beta$. On the other hand, we showed that the same training protocol increased the phosphorylation of ERK in the control group confirming the neuroprotective function performed by ERK. More studies should be conducted to better understand the damage of diabetes mellitus in different brain areas.

\section{Funding}

Grant sponsors: FAPESP (2010/18257-0), CNPQ (142587/2007$9)$.

\section{References}

[1] American Diabetes Association, Diabetes Care, American Diabetes Association, 37, 2014, pp. 581-590. 
[2] E. Cereda, M. Barichella, C. Pedrolli, C. Klersy, E. Cassani, R. Caccialanza, G. Pezzoli, Diabetes and risk of Parkinson's disease. A systematic review and meta-analysis, Diabetes Care 34 (2011) 2614-2623.

[3] Z.S. Qu, Z.X. Jiao, X.J. Sun, Y.W. Zhao, J.P. Ren, G.G. Xu, Effects of streptozotocin-induced diabetes on tau phosphorylation in the rat brain, Brain Res. 1383 (2011) 300-306.

[4] W.L. Xu, E. von Strauss, C.X. Qiu, B. Winblad, L. Fratiglioni, Uncontrolled diabetes increases the risk of Alzheimer's disease: a population-based cohort study, Diabetologia 52 (2009) 1031-1039.

[5] J.A. Obeso, C. Marin, C. Rodriguez-Oroz, J. Blesa, B. Benitez-Temino, J. Mena-Segovia, M. Rodriguez, C.W. Olanow, The basal ganglia in parkinson's disease: current concepts and unexplained observations, Ann. Neurol. 64 (2008) S30-S46

[6] P. Ibanez, A.M. Bonnet, B. Debarges, E. Lohmann, F. Tison, P. Pollak, Y. Agid, A. Durr, A. Brice, G. French Parkinson's Disease, Causal relation between alpha-synuclein gene duplication and familial Parkinson's disease, Lancet 364 (2004) 1169-1171.

[7] J.A. Santiago, J.A. Potashkin, Shared dysregulated pathways lead to Parkinson's disease and diabetes, Trends Mol. Med. 19 (2013) 176-186.

[8] C. Liu, B. Cholerton, M. Shi, C. Ginghina, K.C. Cain, P. Auinger, J. Zhang, D. Parkinson Study Grp, CSF tau and tau/A beta(42) predict cognitive decline in Parkinson's disease, Parkinsonism Relat. Disord. 21 (2015) 271-276.

[9] B. Mollenhauer, C. Trenkwalder, N. von Ahsen, M. Bibl, P. Steinacker, P. Brechlin, J. Schindehuette, S. Poser, J. Wiltfang, M. Otto, Beta-amlyoid 1-42 and tau-protein in cerebrospinal fluid of patients with Parkinson's disease dementia, Dement. Geriatr. Cogn. Disord. 22 (2006) 200-208.

[10] J. Zhang, H.A. Mattison, C. Liu, C. Ginghina, P. Auinger, M.P. McDermott, T Stewart, U.J. Kang, K.C. Cain, M. Shi, P.S.G.D. Investigators, Longitudinal assessment of tau and amyloid beta in cerebrospinal fluid of Parkinson disease, Acta Neuropathol. 126 (2013) 671-682.

[11] S. Takeda, N. Sato, H. Rakugi, R. Morishita, Molecular mechanisms linking diabetes mellitus and Alzheimer disease: beta-amyloid peptide, insulin signaling, and neuronal function, Mol. Biosyst. 7 (2011) 1822-1827.

[12] A. Quesada, B.Y. Lee, P.E. Micevych, PI3 kinase/Akt activation mediates estrogen and IGF-1 nigral DA neuronal neuroprotection against a unilateral rat model of Parkinson's disease, Dev. Neurobiol. 68 (2008) 632-644.

[13] S. Busiguina, J.A. Chowen, J. Argente, I. Torres-Aleman, Specific alterations of the insulin-like growth factor I system in the cerebellum of diabetic rats, Endocrinology 137 (1996) 4980-4987.

[14] L.M. Arantes, N.O. Bertolini, R.F. de Moura, M.A. Rostom de Mello, E. Luciano, Insulin concentrations in cerebellum and body balance in diabetic male rats: aerobic training effects, Physiol. Behav. 118 (2013) 58-62.

[15] T. Paillard, Y. Rolland, P. de Souto Barreto, Protective effects of physical exercise in alzheimer's disease and parkinson's disease: a narrative review, J. Clin. Neurol. 11 (2015) 212-219.

[16] S.S. Yi, Effects of exercise on brain functions in diabetic animal models, World J. Diabetes 6 (2015) 583-597.

[17] C.W. Cotman, N.C. Berchtold, Exercise: a behavioral intervention to enhance brain health and plasticity, Trends Neurosci. 25 (2002) 295-301.

[18] Y.K. Jeon, C.H. Ha, Expression of brain-derived neurotrophic factor, IGF-1 and cortisol elicited by regular aerobic exercise in adolescents, J. Phys. Ther. Sci. 27 (2015) 737-741.

[19] J.A. Curiacos de Almeida Leme, R.J. Gomes, M.A. Rostom de Mello, E. Luciano, Moderate physical training increases brain insulin concentrations in experimental diabetic rats, Indian J. Exp. Biol. 46 (2008) 443-446.

[20] R.J. Gomes, C.A. Machado de Oliveira, C. Ribeiro, C.S. de Alencar Mota, L.P. Moura, L.M. Marcondes Cesar Tognoli, J.A. Curiacos de Almeida Leme, E. Luciano, M.A. Rostom de Mello, Effects of exercise training on hippocampus concentrations of insulin and IGF-1 in diabetic rats, Hippocampus 19 (2009) 981-987.

[21] J.C. Diegues, J.R. Pauli, E. Luciano, J.A. Curiacos de Almeida Leme, L.P. de Moura, R.A. Dalia, M.B. de Araujo, C.Y. Sibuya, M.A. Rostom de Mello, R.J. Gomes, Spatial memory in sedentary and trained diabetic rats: molecular mechanisms, Hippocampus 24 (2014) 703-711.

[22] Voltarelli, TransiçÃo Metabólica E Teste Do Lactato mínimo Em Ratos, NOVA 2005.

[23] F.A. Voltarelli, C.A. Gobatto, M.A. de Mello, Determination of anaerobic threshold in rats using the lactate minimum test, Braz. J. Med. Biol. Res. 35 (2002) 1389-1394.

[24] D. Nogueira, B. Strufaldi, M. Hirata, D. Abdalla, R. Hirata, Métodos De Bioquímica Clínica, Pancast, São Paulo, 1990.

[25] G.J. Biessels, S. Staekenborg, E. Brunner, C. Brayne, P. Scheltens, Risk of dementia in diabetes mellitus: a systematic review, Lancet Neurol. 5 (2006) $64-74$

[26] J. Li, Y.H. Shao, Y.P. Gong, Y.H. Lu, Y. Liu, C.L. Li, Diabetes mellitus and dementia - a systematic review and meta-analysis, Eur. Rev. Med. Pharmacol. Sci. 18 (2014) 1778-1789.
[27] S. Lenzen, The mechanisms of alloxan- and streptozotocin-induced diabetes, Diabetologia 51 (2008) 216-226.

[28] R.J. Gomes, M.A. de Mello, F.H. Caetano, C.Y. Sibuya, C.A. Anaruma, G.P. Rogatto, J.R. Pauli, E. Luciano, Effects of swimming training on bone mass and the GH/IGF-1 axis in diabetic rats, Growth Horm. IGF Res. 16 (2006) 326-331.

[29] E.d. Silva-Costa, A.A. Gonçalves, I.J.L. Brito, C.A.d. Silva, Metformin interacts with physical training decreasing glycemia and increasing glycogen supply in diabetic rats, Revista Brasileira de Medicina do Esporte 14 (2008) 337-340.

[30] R.J. Gomes, J.A. Curiacos de Almeida Leme, L.P. de Moura, M.B. de Araujo, G.P. Rogatto, R.F. de Moura, E. Luciano, M.A. Rostom de Mello, Growth factors and glucose homeostasis in diabetic rats: effects of exercise training, Cell Biochem. Funct. 27 (2009) 199-204.

[31] E. Carro, J.L. Trejo, T. Gomez-Isla, D. LeRoith, I. Torres-Aleman, Serum insulin-like growth factor I regulates brain amyloid-beta levels, Nat. Med. 8 (2002) 1390-1397

[32] J.L. Trejo, E. Carro, I. Torres-Aleman, Circulating insulin-like growth factor mediates exercise-induced increases in the number of new neurons in the adult hippocampus, J. Neurosci. 21 (2001) 1628-1634.

[33] Costa I.P.d, Neurobiologia Da Doença De Alzheimer, 2013.

[34] S.M. de la Monte, J.R. Wands, Review of insulin and insulin-like growth factor expression, signaling, and malfunction in the central nervous system: relevance to Alzheimer's disease, J. Alzheimers Dis. 7 (2005) 45-61.

[35] S. Hoyer, Glucose metabolism and insulin receptor signal transduction in Alzheimer disease, Eur. J. Pharmacol. 490 (2004) 115-125.

[36] S. Hall, Y Surova, A Öhrfelt, H. Zetterberg. D. Lindqvist, O. Hansson, CSF biomarkers and clinical progression of Parkinson disease, Neurology 84 (2015) 57-63.

[37] T. Zhang, B.S. Pan, G.C. Sun, X. Sun, F.Y. Sun, Diabetes synergistically exacerbates poststroke dementia and tau abnormality in brain, Neurochem. Int. 56 (2010) 955-961.

[38] C. Gao, C. Hoelscher, Y. Liu, L. Li, GSK3: a key target for the development of novel treatments for type 2 diabetes mellitus and Alzheimer disease, Rev. Neurosci. 23 (2012) 1-11.

[39] M. Nagao, H. Hayashi, Glycogen synthase kinase-3beta is associated with Parkinson's disease, Neurosci. Lett. 449 (2009) 103-107.

[40] M. Golpich, E. Amini, F. Hemmati, N.M. Ibrahim, B. Rahmani, Z. Mohamed, A.A. Raymond, L. Dargahi, R. Ghasemi, A. Ahmadiani, Glycogen synthase kinase-3 beta (GSK-3ß) signaling: implications for Parkinson's disease, Pharmacol. Res. 97 (2015) 16-26.

[41] H.S. Um, E.B. Kang, J.H. Koo, H.T. Kim, E.J. Jin-Lee Kim, C.H. Yang, G.Y. An, I.H. Cho, J.Y. Cho, Treadmill exercise represses neuronal cell death in an aged transgenic mouse model of Alzheimer's disease, Neurosci. Res. 69 (2011) 161-173.

[42] R. Roskoski Jr., ERK1/2 MAP kinases: structure, function, and regulation, Pharmacol. Res. 66 (2012) 105-143.

[43] J.H. Zhu, S.M. Kulich, T.D. Oury, C.T. Chu, Cytoplasmic aggregates of phosphorylated extracellular signal-regulated protein kinases in Lewy body diseases, Am. J. Pathol. 161 (2002) 2087-2098.

[44] M. Townsend, T. Mehta, D.J. Selkoe, Soluble Abeta inhibits specific signal transduction cascades common to the insulin receptor pathway, J. Biol. Chem. 282 (2007) 33305-33312.

[45] K. Watson, G.H. Fan, Macrophage inflammatory protein 2 inhibits beta-amyloid peptide (1-42)-mediated hippocampal neuronal apoptosis through activation of mitogen-activated protein kinase and phosphatidylinositol 3-kinase signaling pathways, Mol. Pharmacol. 67 (2005) 757-765.

[46] M.J. Savage, Y.G. Lin, J.R. Ciallella, D.G. Flood, R.W. Scott, Activation of c-Jun $\mathrm{N}$-terminal kinase and p38 in an Alzheimer's disease model is associated with amyloid deposition, J. Neurosci. 22 (2002) 3376-3385

[47] G. Frasca, V. Carbonaro, S. Merlo, A. Copani, M.A. Sortino, Integrins mediate beta-amyloid-induced cell-cycle activation and neuronal death, J. Neurosci. Res. 86 (2008) 350-355.

[48] R. Ghasemi, M. Moosavi, A. Zarifkar, K. Rastegar, N. Maghsoudi, The interplay of akt and ERK in abeta toxicity and insulin-Mediated protection in primary hippocampal cell culture, J. Mol. Neurosci. 57 (2015) 325-334.

[49] M.O. Dietrich, C.E. Mantese, L.O. Porciuncula, G. Ghisleni, L. Vinade, D.O. Souza, L.V. Portela, Exercise affects glutamate receptors in postsynaptic densities from cortical mice brain, Brain Res. 1065 (2005) 20-25.

[50] A.P. Muller, M. Cammarota, M.O. Dietrich, L.N. Rotta, L.V. Portela, D.O. Souza, I. Izquierdo, L.R. Bevilaqua, M.L. Perry, Different effect of high fat diet and physical exercise in the hippocampal signaling, Neurochem. Res. 33 (2008) 880-885. 